\title{
Amniotic fluid index versus maximum vertical pocket measurement in predicting perinatal outcome at 40 weeks or beyond
}

\author{
Nasreen Noor ${ }^{1 *}$, Seema Amjad Raza ${ }^{1}$, Shazia Parveen ${ }^{1}$, \\ Mohammad Khalid ${ }^{2}$, Syed Manazir $\mathrm{Ali}^{3}$
}

${ }^{1}$ Department of Obstetrics and Gynecology, ${ }^{2}$ Department of Radiodiagnosis, ${ }^{3}$ Department of Paediatrics, JNMC, AMU, Aligarh, Uttar Pradesh, India

Received: 05 July 2018

Accepted: 10 August 2018

*Correspondence:

Dr. Nasreen Noor,

E-mail: nasreen_71@rediffmail.com

Copyright: () the author(s), publisher and licensee Medip Academy. This is an open-access article distributed under the terms of the Creative Commons Attribution Non-Commercial License, which permits unrestricted non-commercial use, distribution, and reproduction in any medium, provided the original work is properly cited.

\section{ABSTRACT}

Background: The aim of this study is to compare the use of amniotic fluid index with maximum vertical pocket for predicting perinatal outcomes.

Methods: The present study was a prospective observational study and includes 140 The study include normal antenatal women at gestational age 40 weeks or beyond (by last menstrual period $/ 1^{\text {st }}$ trimester scan) referred from antenatal between 20 to 40 years were enrolled in this study from 2015 to 2017. After Institutional Ethics Committee approval all recruited women was assessed at the $3^{\text {rd }}$ trimester visit for baseline demographic and obstetric data. After taking a detailed history and examination the women were subjected to ultrasonography for Amniotic Fluid index (AFI) and Maximum vertical pocket (MVP). The women were divided into 2 groups based on measurement of AFI and MVP ultrasonologically. The correlation of Amniotic fluid index and Maximum vertical pocket with perinatal outcome were computed for the 2 groups: Group Ia - women having normal AFI and normal MVP; Group Ib - women having decreased AFI and normal MVP.

Results: In Group Ia, 31(34.44\%) women were induced and in Group Ib $59(65.56 \%)$ women were induced for oligohydramnios. 65 women $(72.22 \%)$ had normal vaginal delivery versus 25 women $(27.28 \%)$ had undergone LSCS in Group Ia, while in Group Ib, 32 women (64\%) versus 18 women (36\%) had vaginal delivery and LSCS respectively. Higher rate of LSCS was observed in Group Ib. There was no significant difference in the rate of LSCS for fetal distress between Group Ia and Ib for fetal distress.

Conclusions: Amniotic fluid index (AFI) compared with the maximum vertical pocket (MVP) excessively characterizes patients as having oligohydramnios, leading to an increase in obstetric interventions, without any documented improvement in perinatal morbidity and mortality. Thus, authors cannot find any objective reason to favour AFI over MVP.

Keywords: Fetal distress, Hypertension in pregnancy, Stillbirths

\section{INTRODUCTION}

Assessment of amniotic fluid volume (AFV) is an integral part of antenatal ultrasound evaluation during screening exams, targeted anatomy examinations, and in tests assessing fetal well-being. Abnormal AFV has been associated with an increased risk of perinatal mortality and several adverse perinatal outcomes, including premature rupture of membranes (PROM), fetal abnormalities, abnormal birth weight, and increased risk of obstetric interventions by Harman CR. ${ }^{1}$ The ultimate goal of antepartum surveillance program is to improve 
perinatal outcome and to decrease intrauterine fetal demise besides prevention of maternal morbidity and mortality by Yeo et al, Liston R et al. ${ }^{2,3}$ A fetus in distress should be identified at the earliest so that timely delivery will not only salvage the fetus but also prevent long term neurological impairments such as injury to fetal central nervous system by Baschat AA et al. ${ }^{4}$ These risk increases from the expected date of confinement (40 weeks of gestation) as placental insufficiency and postmaturity (greater than 42 weeks of gestation) are associated with an exponential increase in the risk of perinatal death by Bergjs $\emptyset .^{5}$ Delivery beyond 42 weeks is associated with a fourfold increase in death in utero, as well as a threefold increase in neonatal death compared with delivery at term by Crowley P. ${ }^{6}$ In addition to mortality, there is an increased risk of meconium aspiration syndrome, neonatal seizures and long term handicap by Minchom P. ${ }^{7}$ Amniotic fluid assessment by ultrasound is one of the important tools in assessing the fetal health in all risk categories especially beyond the period of viability by Nash $\mathrm{P}^{8}$ Though there are several ways by Dubil EA to assess quantity of amniotic fluid ranging from clinical palpation to measurement of single deepest vertical pocket Nabhan AF et al, amniotic fluid index (AFI) by four-quadrant technique as described by Phelan et al..$^{9-11}$ At term, oligohydramnios increases the risk of labor induction, the deceleration in fetal heart rate (FHR) tracings during labour, and recourse to cesarean delivery. Its effect on adverse neonatal outcome is less clearly documented by Locatelli et al. ${ }^{12}$ Thus, the present study was carried out in an effort to assess relation of maximum vertical pocket and amniotic fluid index with perinatal outcome.

\section{METHODS}

\section{Inclusion criteria}

- The present study was a prospective observational study and includes 140 pregnant women with known last menstrual period, history of regular menstruation, singleton pregnancy, gestational age from 40 weeks or beyond and aged between 20 and 40 years.

\section{Exclusion criteria}

- The exclusion criteria were history of gestational hypertension, diabetes mellitus, intrauterine growth restriction, hydrops fetalis, congenital malformations, twins, polyhydramnios and premature rupture of membranes.

After approval by Institutional Ethics Committee all recruited women were observed for baseline demographic and obstetric data including age, parity and past medical events at first antenatal visit. After taking a detailed history and examination all women provided an informed written consent and underwent ultrasound evaluation for Amniotic Fluid index (AFI) and Maximum vertical pocket (MVP). The women were divided into 2 groups based on measurement of AFI and MVP ultrasonologically:

- Group Ia - women having normal AFI and normal MVP.

- Group Ib - women having decreased AFI and normal MVP.

The correlation of amniotic fluid index and maximum vertical pocket with perinatal outcome were computed for the 2 groups. The primary outcome measures were presence of meconium, rate of diagnosis of oligohydramnios, Apgar score at 1 and 5 minutes, birth weight, admission to NICU, neonatal morbidity and mortality and number of perinatal death while secondary outcome were induction of labor, mode of delivery and rate of caesarean section for fetal distress. The correlation of amniotic fluid index and maximum vertical pocket with perinatal outcome were computed for the 2 groups. $P$ values of less than 0.05 were considered statistically significant.

\section{RESULTS}

In the present study, total of 140 antenatal women were included after fulfilling the inclusion and exclusion criteria. The women were divided into 2 groups based on measurement of AFI and MVP ultrasonologically. Maternal baseline characteristics were similar between the two groups in terms of age, parity and gestational age (Table 1).

Table 1: Demographic profile of the study subjects.

\begin{tabular}{|c|c|c|c|}
\hline Parameters & $\begin{array}{l}\text { Group Ia } \\
(n=90)\end{array}$ & $\begin{array}{l}\text { Group Ib } \\
(n=50)\end{array}$ & p-value \\
\hline $\begin{array}{l}\text { Age (years) } \\
(\text { mean } \pm \text { SD })\end{array}$ & $24.63 \pm 4.13$ & $24.06 \pm 2.98$ & 0.57 \\
\hline \multicolumn{4}{|l|}{ Gravidity } \\
\hline Primi & $39(43.3 \%)$ & $21(42 \%)$ & \multirow{2}{*}{0.9} \\
\hline Multi & $51(56.7 \%)$ & $29(58 \%)$ & \\
\hline \multicolumn{4}{|c|}{ Gestational age } \\
\hline$\geq 40$ weeks & $66(73.3)$ & $37(74)$ & \\
\hline$\geq 41$ weeks & $14(15.6)$ & 09 (18) & \\
\hline$\geq 42$ weeks & $10(11.1)$ & $04(8)$ & \\
\hline
\end{tabular}

In Group Ia, out of 90 women about 31 (34.44\%) were induced and $59(65.56 \%)$ women spontaneously progressed into labour.

Table 2: Rate of diagnosis of oligohydramnios and induction of labour.

\begin{tabular}{|llllll|}
\hline $\begin{array}{l}\text { Induction } \\
\text { of labour }\end{array}$ & \multicolumn{2}{l}{$\begin{array}{l}\text { Group Ia } \\
(\mathrm{n}=90)\end{array}$} & No. & $\%$ & \multicolumn{2}{l|}{$\begin{array}{l}\text { Group Ib } \\
(\mathbf{n}=50)\end{array}$} & No-value \\
\hline Yes & 31 & 34.44 & 50 & $\%$ & \\
\hline No & 59 & 65.56 & 00 & 000 & 0.0001 \\
\hline Total & 90 & 100 & 50 & 100 & \\
\hline
\end{tabular}


In Group Ib, $50(100 \%)$ women were induced for oligohydramnios diagnosed on the basis of decreased AFI $(<5 \mathrm{~cm})$ and had normal MVP $(\geq 2 \mathrm{~cm})$. Hence AFI increases the rate of diagnosis of oligohydramnios and labour induction (Table 2).

Table 3: Mode of delivery.

\begin{tabular}{|lllll|}
\hline Mode of & \multicolumn{2}{l}{ Group Ia $(\mathbf{n = 9 0 )}$} & Group Ib $(\mathbf{n = 5 0})$ \\
delivery & No. & $\mathbf{\%}$ & No. & $\%$ \\
\hline VD & 65 & 72.22 & 32 & 64 \\
\hline LSCS & 25 & 27.78 & 18 & 36 \\
\hline Total & 90 & 100 & 50 & 100 \\
\hline
\end{tabular}

$\chi^{2}=1.02, \mathrm{p}=0.312$

Present study shows that in Group Ia $72.22 \%$ (65 women) had normal vaginal delivery and $27.28 \%$ ( 25 women) undergone LSCS, while in Group Ib 64\% (32 women) had vaginal delivery and $36 \%$ (18 women) had undergone LSCS. It was observed that Group Ia and Group Ib had no significant difference in mode of delivery (Table 3).

Table 4: Indications for LSCS.

\begin{tabular}{|lllll|}
\hline \multirow{2}{*}{ Indication for LSCS } & \multicolumn{2}{c|}{ Group Ia } & \multicolumn{2}{l|}{ Group Ib } \\
\hline Fetal distress with MSAF & 8 & 32 & 9 & 50 \\
\hline $\begin{array}{l}\text { Fetal distress with non } \\
\text { reassuring CTG }\end{array}$ & 8 & 32 & 5 & 27.78 \\
\hline NPOL & 5 & 20 & 3 & 16.67 \\
\hline Failed induction & 4 & 16 & 1 & 5.55 \\
\hline Total & 25 & 100 & 18 & 100 \\
\hline
\end{tabular}

$\chi 2=1.99, \mathrm{p}=0.15$

As shown in Table 4, there was no significant difference in the rate of LSCS for fetal distress $(p=0.15)$. The mean birth weight in present study was $2.96 \pm 0.36$ and there was no significant difference between the birth weights of the two groups. The mean \pm SD of Apgar score at 1 minute was $7.10 \pm 0.30$ and at 5 minutes was $8.14 \pm 0.355$.

There was no significant difference between the groups for Apgar score $(\mathrm{p}=0.9)$. In present study, 2 neonates were admitted in NICU and died later due to valvular heart disease. However, there was no statistical difference between the groups $(\mathrm{p}=0.7)$ (Table 5).

Table 5: Neonatal outcome.

\begin{tabular}{|llll|}
\hline Neonatal outcome & Group Ia & Group Ib & P value \\
\hline Birth weight & 2.96 & 2.99 & 0.6 \\
\hline Meconium & 8 & 9 & 0.1 \\
\hline $\begin{array}{l}\text { Apgar Score }<7 \\
\text { at 5 mins }\end{array}$ & 0 & 0 & 0.9 \\
\hline NICU Admission & 1 & 1 & 0.7 \\
\hline MAS & 0 & 0 & 00 \\
\hline $\begin{array}{l}\text { Neonatal morbidity } \\
\text { and mortality }\end{array}$ & 1 & 1 & 0.7 \\
\hline Perinatal death & 1 & 1 & 0.7 \\
\hline
\end{tabular}

\section{DISCUSSION}

In the present study, total of 130 pregnant women were evaluated. They were randomly divided into two groups: 90 women in Group Ia, 40 women in Group Ib. The study groups were similar in view of demographic characteristics including maternal age, gravidity and gestational age.

In Group Ia, out of 90 women about 31(34.44\%) cases were induced. In Group Ib, 50(100\%) women were induced for oligohydramnios diagnosed on the basis of decreased AFI $(<5 \mathrm{~cm})$ and normal MVP $(\geq 2 \mathrm{~cm})$. Present study is in accordance with AF Nabhan and Kehl S et al and they also concluded that use of AFI increased the rate of diagnosis of oligohydramnios and labour induction for oligohydramnios without improving perinatal outcome in comparison to MVP. ${ }^{10,13}$ Nabhan AF states that the AFI method for fetal surveillance almost doubles the risk for induction of labour. ${ }^{10}$

It was observed in comparing Group Ia and Group Ib that there was no significant difference in mode of delivery. present findings are in accordance with Kehl S et $\mathrm{al}^{13}$. While comparing Group Ia and Group $\mathrm{Ib}$, there was no significant difference in the rate of LSCS for fetal distress between the two groups $(\mathrm{p}=0.15)$. Moses et al study overall rate of caesarean deliveries for fetal distress was $4.8 \%$ and out of which $51 \%$ were in AFI group and $39 \%$ in MVP group and there was no difference in the neonatal outcomes for both the groups. ${ }^{14}$

There was no significant difference for the presence of meconium between Group Ia and Ib. present results are similar to Kehl $\mathrm{S}$ et al who observed no difference in presence of meconium and birth weight between the two groups. ${ }^{13}$ However, Moses et al observed that there was no difference in the rate of meconium being present, but among the neonates with meconium, there was a higher proportion of thick meconium observed in the MVP monitored group. ${ }^{14}$ There was no significant difference between the groups for Apgar score at 1 minute and 5 minutes.

\section{CONCLUSION}

Amniotic fluid index compared with the maximal vertical pocket excessively characterizes patients as having oligohydramnios, leading to an increase in obstetric interventions, without any documented improvement in perinatal mortality and morbidity. However, there was no significant difference in predictability of cesarean section for fetal distress, low Apgar score. Thus, authors cannot find any objective reason to favor AFI over MVP.

\section{ACKNOWLEDGMENTS}

Special thanks to all patients who participated in this study and also to the faculty of Department of Obstetrics and Gynaecology, Department of Radiodiagnosis and 
Department of Pedriatics, JNMC, AMU, Aligarh, Uttar Pradesh, India, who helped and contributed in this study.

Funding: No funding sources

Conflict of interest: None declared

Ethical approval: The study was approved by the Institutional Ethics Committee

\section{REFERENCES}

1. Harman CR. Amniotic fluid abnormalities. Semin Perinatol. 2008;32(4):288-94.

2. Yeo, Ross MG, Vintzileos AM. Antepartum and intrapartum surveillance of the fetus and the amniotic fluid. In: Clinical obstetrics: the fetus and mother. $3^{\text {rd }}$ ed. John Wiley and Sons; 2008:586-606.

3. Liston R, Sawchuck D, Young D, Brassard N, Campbell K, Davies G, et al. Fetal health surveillance: antepartum and intrapartum consensus guideline. J Obstet Gynaecol Canada. 2007;29(9):S3S4.

4. Baschat AA, Viscardi RM, Hussey-Gardner B, Hashmi N, Harman C. Infant neurodevelopment following fetal growth restriction: relationship with antepartum surveillance parameters. Ultrasound Obstet Gynecol. 2009;33(1):44-50.

5. Bergjs $\varnothing$ T. Post-term pregnancy. In: Studd J, ed. Progress in Obsterics and Gynaecology. London: Churchill Livingstone; 1985:121-133.

6. Crowley P. Post-term pregnancy: induction or surveillance? In: Chalmers I, Enkin M, Keirse MJNC, eds. Effective care in pregnancy and childbirth. Oxford: Oxford University Press; 1989:776-791.

7. Minchom P, Niswander K, Chalmers I, Dauncey M, Newcombe R, Elbourne D, et al. Antecedents and outcome of very early neonatal seizures in infants born at or after term. $\mathrm{Br} \mathrm{J}$ Obstet Gynaecol. 1987;94:431-9.
8. Patricia Nash NNP-BC MS. Amniotic fluid index. Neonatal Network. 2013;32(1):46.

9. Dubil EA, Magann EF. Amniotic fluid as a vital sign for fetal wellbeing. Australasian J Ultrasound Med. 2013;16(2):62-70.

10. Nabhan AF, Abdelmoula YA. Amniotic fluid index versus single deepest vertical pocket as a screening test for preventing adverse pregnancy outcome. Cochrane Database of Systematic Reviews. 2008(3).

11. Phelan JP, Ahn MO, Smith CV, Rutherford SE, Anderson E. Amniotic fluid index measurements during pregnancy. J Reprod Med. 1987;32(8):601-4.

12. Locatelli A, Vergani P, Toso L, Verderio M, Pezzullo JC, Ghidini A. Perinatal outcome associated with oligohydramnios in uncomplicated term pregnancies. Arch Gynecol Obstet. 2004;269(2):130$3 \mathrm{~S}$.

13. Kehl S, Schelkle A, Thomas A, Puhl A, Meqdad K, Tuschy B, et al. Single deepest vertical pocket or amniotic fluid index as evaluation test for predicting adverse pregnancy outcome (SAFE trial): a multicenter, open-label, randomized controlled trial. Ultrasound Obstet Gynecol. 2016;47(6):674-9.

14. Moses J, Doherty D, Magann EF, Chauhan SP, Morrison JC. A randomized clinical trial of the intrapartum assessment of amniotic fluid volume: amniotic fluid index versus the single deepest pocket technique. Am J Obstet Gynecol. 2004;190:1564-9.

Cite this article as: Noor N, Raza SA, Parveen S, Khalid M, Ali SM. Amniotic fluid index versus maximum vertical pocket measurement in predicting perinatal outcome at 40 weeks or beyond. Int $\mathbf{J}$ Reprod Contracept Obstet Gynecol 2018;7:4887-90. 